\title{
CLINICAL BABESIOSIS AND MOLECULAR IDENTIFICATION OF BABESIA CANIS AND BABESIA GIBSONI INFECTIONS IN DOGS FROM SERBIA
}

\author{
Darko DAVITKOV $^{1 *}$, Milos VuCiCEVIC ${ }^{1}$, Jevrosima Stevanovic ${ }^{2}$, Vanja Krstic ${ }^{1}$, \\ Snezana TOMANOVIC ${ }^{3}$, Uros GLAVINIC ${ }^{2}$ and Zoran STANIMIROVIC $^{2}$ \\ ${ }^{1}$ Department of Equine, Small Animal, Poultry and Wild Animal Diseases and \\ ${ }^{2}$ Department of Biology, Faculty of Veterinary Medicine, University of Belgrade, \\ Bul. oslobodjenja 18, 11000 Belgrade, Serbia; ${ }^{3}$ Laboratory for Medical Entomology, \\ Department for Parasitology, Institute for Medical Research, University of Belgrade, \\ Belgrade, Serbia
}

(Received 23 August 2014; accepted 17 February 2015)

Canine babesiosis is a frequent and clinically significant tick-borne disease. Sixty symptomatic dogs with clinical findings compatible with babesiosis were included in this study conducted in Serbia. After clinical examination, blood samples were taken for microscopic examination, complete blood count (CBC), Canine SNAP 4Dx Test, DNA analyses and sequencing. The main clinical signs included apathy, anorexia, fever, brown/red discoloration of urine, pale mucous membranes, icterus, splenomegaly, and vomiting. The main clinicopathological findings in Babesia infections were a slight to severe thrombocytopenia and a mild to very severe normocytic normochromic anaemia. Microscopic evaluation revealed 58 positive samples with the presence of large and small intraerythrocytic piroplasms in 57 and 1 sample(s), respectively. No co-infections were found using SNAP test. Two Babesia species, B. canis (58/60) and B. gibsoni (2/60), were differentiated by polymerase chain reaction-restriction fragment length polymorphism (PCR-RFLP). Species identification was further confirmed by sequencing PCR products of $B$. gibsoni samples and six randomly selected $B$. canis samples. All dogs were treated with imidocarb dipropionate $(6.6 \mathrm{mg} / \mathrm{kg}$ of body weight), given intramuscularly twice at an interval of 14 days. This report presents the first molecular evidence of the occurrence of B. gibsoni and B. canis, confirmed by DNA sequencing, in sick dogs from Serbia.

Key words: Babesia canis/gibsoni, dogs, clinical signs, PCR-RFLP, sequencing, Serbia

Canine babesiosis is a frequent protozoan tick-borne disease with worldwide distribution and global significance (Irwin, 2009; Solano-Gallego and Baneth, 2011). Causative agents of canine babesiosis (piroplasmosis) are in-

*Corresponding author; E-mail: davitkov.darko@gmail.com; Phone: 00381 (11) 3611-809; Fax: 00381 (11) 3611-809 
traerythrocytic protozoa of the genera Babesia and Theileria (Irwin, 2009). The clinical manifestations of disease can vary from subclinical to severe or fatal. The severity of the disease depends on the species involved, the age and immune status of the host, and concurrent infections (Irwin, 2009). Clinical signs include pale mucous membranes, fever, anorexia, lethargy, splenomegaly, hypotension and water hammer pulse (Matijatko et al., 2012). Four species that can cause Babesia infection have been identified by molecular studies undertaken in Europe so far: Babesia canis, B. vogeli, B. gibsoni and B. microti-like, also known as Theileria annae or Babesia sp. 'Spanish dog' (Solano-Gallego and Baneth, 2011; Matijatko et al., 2012). Predominant vectors for the abovementioned species are Dermacentor reticulatus (B. canis), Rhipicephalus sanguineus (B. vogeli), Haemaphysalis longicornis (B. gibsoni) and the main candidate vector of B. microti-like is Ixodes hexagonus (Solano-Gallego and Baneth, 2011). There are some reports suggesting that direct dog to dog transmission, via bite wounds, is highly likely and might possibly be the main mode of transmission of B. gibsoni (Jefferies et al., 2007; Yeagley et al., 2009). Also, it has been demonstrated that $B$. gibsoni infection can be transmitted transplacentally (Fukumoto et al., 2005).

For many years, Babesia has been detected using stained blood smears as a standard diagnostic technique. Size and morphology of the intraerythrocytic piroplasm have been the main parameters in diagnosing Babesia spp. However, some Babesia species that lead to different clinical manifestations cannot be morphologically distinguished (Kjemtrup et al., 2000; Jefferies et al., 2007). These Babesia species can be differentiated by molecular methods and not by the blood smear method (Criado-Fornelio et al., 2003). Moreover, molecular methods have other significant advantages, i.e. higher sensitivity and specificity, over the evaluation of peripheral blood smears for detecting canine babesiosis (Bashiruddin et al., 1999). Analyses of DNA sequences are extremely useful in species identification, and the PCR-RFLP technique is faster, more affordable and thus often used in routine molecular identification of unicellular protozoan parasite species (Solano-Gallego et al., 2008; Stevanovic et al., 2011; Stevanovic et al., 2013). It is important for veterinary science to track the prevalence and clinicopathological aspects of Babesia species infecting dogs around the world.

Effective management of dogs with piroplasmosis involves both specific and supportive treatment. Large forms of Babesia are commonly treated with imidocarb dipropionate with good clinical response, while small forms of Babesia appear to be more difficult to treat and imidocarb is less effective (SolanoGallego and Baneth, 2011). Diminazene aceturate used for the treatment of infections by both large and small Babesia spp. has a relatively narrow dose safety margin, it is also relatively toxic, and severe side effects have been reported following its use (Miller et al., 2005; Sakuma et al., 2009). Alternative therapy with the combination of the anti-malarial atovaquone and the macrolide azithromycin 
has been recommended for the treatment of Babesia gibsoni infection (Birkenheuer et al., 2004). The aim of supportive treatment is to restore adequate tissue oxygenation by the correction of anaemia and through rehydration. Prevention is very important when it comes to babesiosis and it requires dogs to be kept free of tick exposure (collars, spot-on formulations or sprays), to avoid fighting with other dogs, and any blood transfusions should be carefully screened to ensure the absence of pathogens (Irwin, 2009).

To date, no data on molecular detection or genetic characterisation of Babesia species in dogs have been documented for Serbia. There is no information about the epidemiology of canine babesiosis in Serbia either. The aim of this study was to identify the species responsible for canine babesiosis in Serbia, as well as to monitor clinical manifestations and some clinical findings of dogs with Babesia canis or B. gibsoni infection.

\section{Materials and methods}

\section{Dogs, samples and laboratory tests}

Sixty symptomatic dogs with clinical findings compatible with babesiosis were studied from November 2012 to January 2014. All dogs were admitted to the Teaching Hospital at the Faculty of Veterinary Medicine in Belgrade for medical consultation and assistance. All relevant data (e.g. age, breed, gender, history of previous tick infestation, major clinical signs) of the patients were collected and recorded by the veterinarians during clinical examination. All dogs were from the Belgrade area and had no recorded history of travelling outside Serbia.

Venous blood samples were collected into sterile tubes with anticoagulant (EDTA) by cephalic venipuncture. Complete blood count (CBC) was performed by IDEXX ProCyte Dx (IDEXX Laboratories, USA). Dogs were considered anaemic when the haematocrit was lower than $37 \%$. The severity of anaemia was classified as described elsewhere (Weiss and Tvedten, 2012). Thrombocytopenia was classified as slight $\left(142-100 \times 10^{9}\right.$ platelets/L), mild $\left(99-50 \times 10^{9}\right.$ platelets/L), moderate $\left(49-25 \times 10^{9}\right.$ platelets/L) and severe $\left(<25 \times 10^{9}\right.$ platelets/L) (Furlanello et al., 2005).

Thin smears were prepared from blood taken from ear punctures of all dogs, stained with Diff-Quick ${ }^{\circledR}$-type stain (Medion Diagnostics GmbH, Düdingen, Switzerland) and examined by light microscopy for the evidence of possible intraerythrocytic piroplasms. All the blood samples were tested by Canine SNAP 4Dx Test (Canine Heartworm Antigen - Anaplasma phagocytophilum - Borrelia burgdorferi - Ehrlichia canis Antibody Test Kit, IDEXX Laboratories, Inc., USA). 


\section{DNA extraction, $P C R$ and $R F L P-P C R$}

DNA was isolated from the blood samples using QIAamp DNA Blood Mini Kit (Qiagen) according to the manufacturer's recommendations. To detect Babesia parasites, all samples were subjected to PCR using primers PIRO-A (5'AATACCCAATCCTGACACAGGG-3') and PIRO-B (5'-TTAAATACGAAT GCCCCCAAC-3') designed to amplify a specific fragment of approximately $410 \mathrm{bp}$ of the 18S-rRNA gene of Babesia spp. (Olmeda et al., 1997). All PCRs were performed using a Multigene Gradient Thermal Cycler (Labnet International Inc.) in $25-\mu \mathrm{L}$ volumes containing $1 \times$ PCR buffer (Kapa Biosystems), $1.5 \mathrm{mM} \mathrm{MgCl}_{2}$ (Kapa Biosystems), $100 \mu \mathrm{M}$ dNTP (Kapa Biosystems), $2 \mu \mathrm{M}$ of each primer, $0.5 \mathrm{U}$ of $T a q$ polymerase (Kapa Biosystems) and $5 \mu \mathrm{L}$ of template DNA. The PCR parameters for amplification were as follow: initial DNA denaturation of $3 \mathrm{~min}$ at $95{ }^{\circ} \mathrm{C}$ followed by 40 cycles of $30 \mathrm{~s}$ at $94{ }^{\circ} \mathrm{C}, 30 \mathrm{~s}$ at $62{ }^{\circ} \mathrm{C}$ and $1 \mathrm{~min}$ at $72{ }^{\circ} \mathrm{C}$, and terminated with a final extension step at $72{ }^{\circ} \mathrm{C}$ for $7 \mathrm{~min}$. Amplification products were separated on a $\%$ agarose gel stained with ethidium bromide and visualised under UV light. A commercial O'RangeRuler ${ }^{\mathrm{TM}} 100 \mathrm{bp}$ DNA Ladder (Fermentas) was used as a size marker.

PCR-RFLP method by Solano-Gallego et al. (2008) was applied to differentiate Babesia species. Digestion of PCR products with TaqI and HinfI enzymes (Thermo Scientific) was performed according to the manufacturer's instructions. RFLP products were separated on a 3\% agarose gel stained with ethidium bromide and visualised under UV light.

To confirm the PCR-RFLP results, all B. gibsoni and 6 randomly selected $B$. canis PCR products were directly sequenced in two directions using the BigDye ${ }^{\circledR}$ Terminator method in an ABI 3730XL automatic DNA sequencer (Macrogen Europe, The Netherlands). Sequence similarity analysis was performed using the BioEdit version 7.2.5 and Clustal W software. Sequence homology searches were made using the online version of BLAST software (available at http://blast.ncbi.nlm.nih.gov). Finally, the representative sequences were deposited in GenBank (accession numbers for B. gibsoni: KJ696716, KJ696717; accession numbers for B. canis: KJ696714, KJ696715).

\section{Results}

\section{Clinical data}

Babesiosis was more frequently detected in males than in females $(80 \%$ and $20 \%$, respectively). The youngest infected dog was 2.5 months old and the oldest was 13 years old. Sixty-seven percent of reported canine babesiosis cases were young and middle-aged dogs (less than 5 years old). Various breeds were represented. The disease was more often diagnosed in purebred dogs $(81.7 \%)$. 
Both $B$. gibsoni infected dogs were of fighting breeds. Ticks were found on 33 of the dogs $(55 \%)$ during clinical examination or earlier by the owner. In 12 cases $(20 \%)$ dog owners reported prevention against ticks as follows: seven dogs were treated with permethrin-based spot-on products, four of them with fipronil-based spot-on formulations, and one dog had a collar with deltamethrin.

According to the owners' assessments, the time span between the onset of clinical signs and arrival at the clinic varied from one to seven days. Routine physical examination of the dogs revealed clinical signs compatible with babesiosis: apathy $(98 \%)$, anorexia $(88.3 \%)$, fever $(78.3 \%)$, brown/red discoloration of urine $(51.7 \%)$, pale mucous membranes $(50 \%)$, icterus $(28.3 \%)$, splenomegaly (28.3\%), vomiting (26.7\%), modified faeces (11.7\%) and ataxia $(6.7 \%)$.

Thrombocytopenia was present in 59/60 (98.3\%) and classified as slight in $4 / 60(6.7 \%)$, mild in $5 / 60(8.3 \%)$, moderate in $7 / 60(11.7 \%)$ and severe in $43 / 60$ (71.7\%). Anaemia was present in 32/60 (53.3\%) and further classified as mild in $9 / 60(15 \%)$, moderate in $10 / 60(16.7 \%)$, severe in $9 / 60(15 \%)$ and very severe in $4 / 60(6.67 \%)$. In the majority of cases, the anaemia was normocytic and normochromic. Forty-three out of 60 (71.7\%) dogs had lymphopenia, 19/60 (31.7\%) leukopenia and 10/60 (16.7\%) neutropenia. Leukocytosis was present in six dogs $(10 \%)$ and neutrophilia in seven $(11.7 \%)$.

\section{Blood smears and snap test}

Intraerythrocytic large, pear-shaped forms morphologically compatible with Babesia spp. were observed in the stained blood smears of 57 dogs $(57 / 60$, $95 \%)$. In one case $(1 / 60,1.67 \%)$ much smaller oval or signet ring-shaped intraerythrocytic parasites were detected in thin blood smears. No co-infections were detected using Canine SNAP 4Dx Test.

\section{Molecular analysis}

Sixty blood samples from dogs with clinical signs suggestive of canine babesiosis were analysed using the molecular method. All blood samples were positive in the Babesia genus-specific PCR. RFLP analysis showed that 58 blood samples $(96.7 \%)$ had restriction profiles similar to $B$. canis, and two samples were similar to $B$. gibsoni (3.3\%). No case of B. vogeli was found.

Results of the sequence analysis demonstrated $100 \%$ correspondence to PCR-RFLP-diagnosed Babesia species. The sequences obtained from all eight dogs were $100 \%$ homologous to sequences from $B$. canis and B. gibsoni present in GenBank. Four B. canis sequences were found to be identical with the $18 \mathrm{~S}$ rRNA GenBank-deposited gene sequences of $B$. canis of dogs originating from France (GenBank accession no. KC902833.1), Hungary (DQ181653.1), Poland (AY321119.1), Croatia (AY072926.1), Russia (AY962187.1), and two B. canis sequences were found to be identical with the gene sequences of $B$. canis of dogs 
originating from Turkey (KF499115.1), Romania (HQ662634.1), Russia (AY649326.1) and Hungary (DQ181656.1).

Two $B$. gibsoni $18 \mathrm{~S}$ rDNA partial sequences showed the highest similarity (100\% correspondence) with sequences obtained from naturally infected dogs in India (GenBank accession no. KF878947.1), China (HG328237.1), Saint Kitts and Nevis (JX112784.1), Japan (AB478330.1), Taiwan (FJ769388.1), USA (EU084677.1), Australia (AY102164.1) and Spain (AY278443.1).

\section{Therapy and outcome}

All dogs with diagnosed babesiosis in this study received a specific treatment with imidocarb dipropionate given by deep intramuscular injection in a dose of $6.6 \mathrm{mg} / \mathrm{kg}$ body weight. The same treatment was repeated after two weeks. The mortality rate of dogs infected with $B$. canis was $8.62 \%$, and that of dogs infected with $B$. gibsoni was $50 \%$.

\section{Discussion}

This is the first report of molecular detection of Babesia canis and B. gibsoni in naturally infected dogs from Serbia. This study also presents the first evidence of B. gibsoni in Serbia confirmed through DNA sequencing. Such results provide important information for both Serbia and Europe regarding the occurrence of $B$. gibsoni.

Several Babesia species can infect dogs all over Europe and produce different clinical signs. Babesia canis is the most commonly found species in temperate regions of Europe. Several studies have detected this species in dogs from Hungary, Croatia, Italy, Poland, Spain, Switzerland, Portugal, Russia, Germany, Slovenia, France, Albania, the Netherlands, Norway (Solano-Gallego and Baneth, 2011) and Romania (Ionita et al., 2012). Babesia gibsoni infection has been described in some European countries using molecular methods: two dogs in Germany (Hartelt et al., 2007), four in Spain (Criado-Fornelio et al., 2003; Tabar et al., 2009), one dog in Italy (Trotta et al., 2009), 14 dogs in Romania (Imre et al., 2013) and six from Croatia were diagnosed with B. gibsoni subclinical infection (Beck et al., 2009). Our results support previous findings reported from neighbouring countries that $B$. canis is considered the main species which causes canine babesiosis in this part of Europe.

The clinical manifestations of canine babesiosis reported in this study are very similar to those described in other European countries. Babesiosis in Serbia occurred more often in males $(80 \%)$ than in females $(20 \%)$, which is consistent with previous reports from other countries (Máthé et al., 2006; Adaszek et al., 2011; René-Martellet et al., 2013). The obvious dominance of male dogs among our patients can be explained probably by the dog-keeping habits and the over- 
representation of males in the population of dogs at risk rather than by true gender predisposition. This study confirmed that young dogs are at greatest risk of canine babesiosis (Bourdoiseau, 2006; Adaszek et al., 2011; René-Martellet et al., 2013). In this study, babesiosis was diagnosed more often in purebred dogs than in mixed-breed dogs. However, babesiosis had not been associated with any particular breed but rather with the dogs' living conditions and the nature of their work (Bourdoiseau, 2006).

The main clinicopathological findings in Babesia infections described in the present study were slight to severe thrombocytopenia, mild to very severe anaemia, lymphopenia and leukopenia. These results correspond well to the abnormalities reported previously (Furlanello et al., 2005; Zygner et al., 2007; Solano-Gallego et al., 2008).

Bearing in mind that there were only two confirmed cases of B. gibsoni in Serbia so far (presented in this study), it is hard to make a comparative analysis of the clinical signs and findings in dogs infected with different Babesia species. This should be followed up in the future together with results of the therapy undertaken. The absence of $B$. vogeli-infected dogs in this research may be explained by the fact that only animals with symptoms characteristic of babesiosis were examined, and that infection with this species usually takes a nearly or absolutely asymptomatic course in adult immunocompetent dogs (Uilenberg et al., 1989; Carret et al., 1999).

In this study, Babesia infection was confirmed by both morphological and molecular detection methods in 58 cases. Small Babesia was proved to be B. gibsoni, and all cases of large Babesia were B. canis. However, two dogs that had not been diagnosed with Babesia infection using light microscopy, were later confirmed to be infected by PCR, one with $B$. canis and the other with $B$. gibsoni. This confirmed the higher sensitivity of molecular techniques in comparison with microscopic examination, as has been found previously (Macintire et al., 2002; Imre et al., 2013).

Both cases of $B$. gibsoni infection detected in this study may be considered autochthonous because these animals had been born in Serbia and had never been taken abroad. The same refers to $B$. canis, whose presence was proven in vector species, D. reticulatus and D. marginatus, in Serbia (Mihaljica et al., 2012).

Both B. gibsoni-infected dogs were of fighting breeds (American Staffordshire terrier and Tosa-Inu). Examination of the Tosa showed the presence of many scars on the head and neck, resulting from bite wounds. Despite the fact that the owner of the Tosa dog reported tick exposure a week before, these dog bites may be important from the epidemiological point of view because studies conducted in the United States (Yeagley et al., 2009) and Australia (Jefferies et al., 2007) indicated that direct dog-to-dog transmission is very likely, most notably through bite wounds. The other case was of a young, 11-month-old American Staffordshire terrier with no history of tick exposure. We tried to track down its 
mother and siblings because transplacental transmission of $B$. gibsoni has been reported (Fukumoto et al., 2005) but without luck.

The fact that $20 \%$ of infected dogs in this research contracted babesia despite appropriate tick control by means of insecticide collars or spot-on preparations indicates that the prevention of canine babesiosis is not as easy as it may seen, nor is it always successful. The success of prevention is affected not only by the active substance but also by other factors which were not under our control: i.e. whether the composition is administered in the right dose and in the right way. The drug of choice for therapeutic treatment was imidocarb dipropionate, the only drug approved for the treatment of canine babesiosis in Serbia. In $B$. gibsoni cases there was no time or need to try other therapeutic protocols, because one dog died shortly after the clinical examination and the other was better after therapy which included imidocarb dipropionate. In this study the mortality of dogs infected with $B$. canis reached $8.62 \%$. Numerous studies on babesiosis caused by the same species, which were carried out in Europe, indicate that the mortality ranges from $1.5 \%$ to $20 \%$, being the highest in Hungary $(20 \%)$ (Máthé et al., 2006) and Croatia (11 to 13.9\%) (Matijatko et al., 2009; Matijatko et al., 2010; Crnogaj et al., 2010) and the lowest (1.5\%) in France (Martinod et al., 1986). However, due to the small number of dogs infected with B. gibsoni, to comment on the mortality rate in these animals is not justifiable.

The clinicopathological findings are restricted to blood count alterations. Since biochemistry alterations were not studied, there is no information about possible organ dysfunctions.

In conclusion, the results of this study confirm the presence of $B$. canis and B. gibsoni in symptomatic dogs from Serbia as well as the usefulness of PCRRFLP for precise identification of the causative species and for epidemiological studies. Examination of symptomatic dogs is of great importance, but asymptomatic dogs should be examined as well. Fast and precise diagnostics allow us to start with adequate therapy on time and to prevent possible complications to the greatest possible extent.

\section{Acknowledgement}

This study was supported by the Ministry of Education, Science and Technological Development of the Republic of Serbia (Grant No. III46002), led by Professor Zoran Stanimirovic.

\section{References}

Adaszek, L., Martinez, A. C. and Winiarczyk, S. (2011): The factors affecting the distribution of babesiosis in dogs in Poland. Vet. Parasitol. 181, 160-165.

Bashiruddin, J. B., Cammà, C. and Rebêlo, E. (1999): Molecular detection of Babesia equi and Babesia caballi in horse blood by PCR amplification of part of the 16S rRNA gene. Vet. Parasitol. 84, 75-83. 
Beck, R., Vojta, L., Mrljak, V., Marinculic, A., Beck, A., Zivicnjak, T. and Caccio, S. M. (2009): Diversity of Babesia and Theileria species in symptomatic and asymptomatic dogs in Croatia. Int. J. Parasitol. 39, 843-848.

Birkenheuer, A. J., Levy, M. G. and Breitschwerdt, E. B. (2004): Efficacy of combined atovaquone and azithromycin for therapy of chronic Babesia gibsoni (Asian genotype) infections in dogs. J. Vet. Intern. Med. 18, 494-498.

Bourdoiseau, G. (2006): Canine babesiosis in France. Vet. Parasitol. 138, 118-125.

Carret, C., Walas, F., Carcy, B., Grande, N., Précigout, É., Moubri, K., Schetters, T. P. and Gorenflot, A. (1999): Babesia canis canis, Babesia canis vogeli, Babesia canis rossi: differentiation of the three subspecies by a Restriction Fragment Length Polymorphism analysis on amplified small subunit ribosomal RNA genes. J. Eukaryot. Microbiol. 46, 298-301.

Criado-Fornelio, A., Gonzalez-del-Rio, M. A., Buling-Sarana, A. and Barba-Carretero, J. C. (2003): Molecular characterization of a Babesia gibsoni isolate from a Spanish dog. Vet. Parasitol. 117, 123-129.

Crnogaj, M., Petlevski, R., Mrljak, V., Kiš, I., Torti, M., Kučer, N., Matijatko, V., Saćer, I. and Štoković, I. (2010): Malondialdehyde levels in serum of dogs infected with Babesia canis. Vet. Med. Czech 4, 163-171.

Fukumoto, S., Suzuki, H., Igarashi, I. and Xuan, X. (2005): Fatal experimental transplacental Babesia gibsoni infections in dogs. Int. J. Parasitol. 35, 1031-1035.

Furlanello, T., Fiorio, F., Caldin, M., Lubas, G. and Solano-Gallego, L. (2005): Clinicopathological findings in naturally occurring cases of babesiosis caused by large form Babesia from dogs of northeastern Italy. Vet. Parasitol. 134, 77-85.

Hartelt, K., Rieker, T., Oehme, R. M., Brockmann, S. O., Muller, W. and Dorn, N. (2007): First evidence of Babesia gibsoni (Asian genotype) in dogs in Western Europe. Vector Borne Zoonotic Dis. 7, 163-166.

Imre, M., Farkas, R., Ilie, M. S., Imre, K. and Dărăbuş, G. (2013): Survey of babesiosis in symptomatic dogs from Romania: Occurrence of Babesia gibsoni associated with breed. Ticks Tick Borne Dis. 4, 500-502.

Ionita, M., Mitrea, I. L., Pfister, K., Hamel, D., Buzatu, C. M. and Silaghi, C. (2012): Canine babesiosis in Romania due to Babesia canis and Babesia vogeli: a molecular approach. Parasitol. Res. 110, 1659-1664.

Irwin, P. J. (2009): Canine babesiosis: from molecular taxonomy to control. Parasit. Vectors 2 (Suppl. 1), S4.

Jefferies, R., Ryan, U. M., Jardine, J., Broughton, D. K., Robertson, I. D. and Irwin, P. J. (2007): Blood, Bull Terriers and babesiosis: further evidence for direct transmission of Babesia gibsoni in dogs. Aust. Vet. J. 85, 459-463.

Kjemtrup, A. M., Kocan, A. A., Whitworth, L., Meinkoth, J., Birkenheuer, A. J., Cummings, J., Boudreaux, M. K., Stockham, S. L., Irizarry-Rovira, A. and Conrad, P. A. (2000): There are at least three genetically distinct small piroplasms from dogs. Int. J. Parasitol. 30, $1501-1505$.

Macintire, D. K., Boudreaux, M. K., West, G. D., Bourne, C., Wright, J. C. and Conrad, P. A. (2002): Babesia gibsoni infection among dogs in the south-eastern United States. J. Am. Vet. Med. Assoc. 220, 325-329.

Martinod, S., Laurent, N. and Moreau, Y. (1986): Resistance and immunity of dogs against Babesia canis in an endemic area. Vet. Parasitol. 19, 245-254.

Máthé, A., Vörös, K., Papp, L. and Reiczigel, J. (2006): Clinical manifestations of canine babesiosis in Hungary (63 cases). Acta Vet. Hung. 54, 367-385.

Matijatko, V., Kiš, I., Torti, M., Brkljačić, M., Barić, R., Žvorc, Z. and Mrljak, V. (2010): Systemic inflammatory response syndrome and multiple organ dysfunction syndrome in canine babesiosis. Vet. Arhiv 80, 611-626.

Matijatko, V., Kiš, I., Torti, M., Brkljačić, M., Kučer, N., Barić, R., Grden, D., Živičnjak, T. and Mrljak, V. (2009): Septic shock in canine babesiosis. Vet. Parasitol. 162, 263-270. 
Matijatko, V., Torti, M. and Schetters, T. P. (2012): Canine babesiosis in Europe: how many diseases? Trends Parasitol. 28, 99-105.

Mihaljica, R., Radulović, Ž., Tomanović, S., Ćakić, S., Penezić, A. and Milutinović, M. (2012): Molecular detection of Babesia spp. in ticks in North Serbia. Arch. Biol. Sci. 64, 1591-1598.

Miller, D. M., Swan, G. E., Lobetti, R. G. and Jacobson, L. S. (2005): The pharmacokinetics of diminazene aceturate after intramuscular administration in healthy dogs. J. S. Afr. Vet. Assoc. 76, 146-150.

Olmeda, A. S., Armstrong, P. M., Rosenthal, B. M., Valladares, B., del Castillo, A., de Armas, F., Miguelez, M., Gonzalez, A., Rodriguez, J. A., Spielman, A. and Telford 3rd, S. R. (1997): A subtropical case of human babesiosis. Acta Trop. 67, 229-234.

René-Martellet, M., Chêne, J., Chabanne, L., Chalvet-Monfray, K. and Bourdoiseau, G. (2013): Clinical signs, seasonal occurrence and causative agents of canine babesiosis in France: Results of multiregional study. Vet. Parasitol. 197, 50-57.

Sakuma, M., Setoguchi, A. and Endo, Y. (2009): Possible emergence of drug resistant variants of Babesia gibsoni in clinical cases treated with atovaquone and azithromycin. J. Vet. Intern. Med. 23, 493-498.

Solano-Gallego, L. and Baneth, G. (2011): Babesiosis in dogs and cats - expanding parasitological and clinical spectra. Vet. Parasitol. 181, 48-60.

Solano-Gallego, L., Trotta, M., Carli, E., Carcy, B., Caldin, M. and Furlanello, T. (2008): Babesia canis canis and Babesia canis vogeli clinicopathological findings and DNA detection by means of PCR-RFLP in blood from Italian dogs suspected of tick-borne disease. Vet. Parasitol. 157, 211-221.

Stevanovic, J., Simeunovic, P., Gajic, B., Lakic, N., Radovic, D., Fries, I. and Stanimirovic, Z. (2013): Characteristics of Nosema ceranae infection in Serbian honey bee colonies. Apidologie 44, 522-536.

Stevanovic, J., Stanimirovic, Z., Genersch, E., Kovacevic, R. S., Ljubenkovic, J., Radakovic, M. and Aleksic, N. (2011): Dominance of Nosema ceranae in honey bees in the Balkan countries in the absence of symptoms of colony collapse disorder. Apidologie 42, 49-58.

Tabar, M. D., Francino, O., Altet, L., Sánchez, A., Ferrer, L. and Roura, X. (2009): PCR survey of vector borne pathogens in dogs living in and around Barcelona, an area endemic for leishmaniosis. Vet. Rec. 164, 112-116.

Trotta, M., Carli, E., Novari, G., Furlanello, T. and Solano-Gallego, L. (2009): Clinicopathological findings, molecular detection and characterization of Babesia gibsoni infection in a sick dog from Italy. Vet. Parasitol. 165, 318-322.

Uilenberg, G., Franssen, F. F., Perie, N. M. and Spanjer, A. A. (1989): Three groups of Babesia canis distinguished and a proposal for nomenclature. Vet. Q. 11, 33-40.

Weiss, D. and Tvedten, H. (2012): Erythrocyte Disorders. In: Willard, M. D. and Tvedten, H. (eds) Small Animal Clinical Diagnosis by Laboratory Methods. Fifth edition. W. B. Saunders, Philadelphia. pp. 38-62.

Yeagley, T. J., Reichard, M. V., Hempstead, J. E., Allen, K. E., Parsons, L. M., White, M. A., Little, S. E. and Meinkoth, J. H. (2009): Detection of Babesia gibsoni and the canine small Babesia 'Spanish isolate' in blood samples obtained from dogs confiscated from dog fighting operations. J. Am. Vet. Med. Assoc. 235, 535-539.

Zygner, W., Gojska, O., Rapacka, G., Jaros, D. and Wedrychowicz, H. (2007): Hematological changes during the course of canine babesiosis caused by large Babesia in domestic dogs in Warsaw (Poland). Vet. Parasitol. 145, 146-151. 